\title{
Phase-Controlled Synthesis of Pd-Sn Nanocrystal Catalysts of Defined Size and Shape
}

Sandra L. A. Bueno, ${ }^{1}$ Xun Zhan, ${ }^{2}$ Joshua Wolfe, ${ }^{1}$ Kaustav Chatterjee, ${ }^{1}$ and Sara E. Skrabalak ${ }^{1, *}$

${ }^{1}$ Department of Chemistry, Indiana University - Bloomington, 800 E. Kirkwood Ave.,

Bloomington, IN 47405.

${ }^{2}$ Electron Microscopy Center, Indiana University - Bloomington, 800 E. Kirkwood Ave., Bloomington, IN 47405

*corresponding author email: sskrabal@indiana.edu 

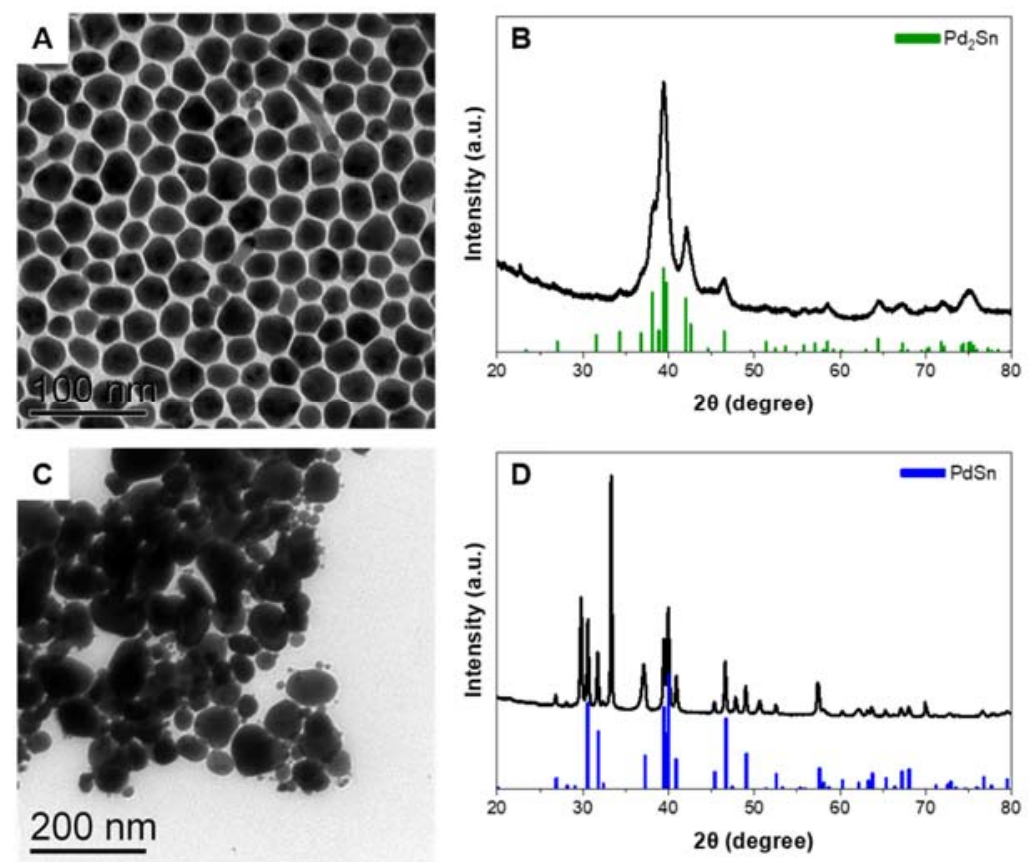

Figure S1. TEM images and corresponding XRD pattern of the obtained Pd-Sn NPs when the Pd:Sn input ratios were (A) 3:1 and (B) 1:2. Green and blue XRD references patterns correspond to $\mathrm{Pd}_{2} \mathrm{Sn}$ (ICDD 01076-2812) and PdSn (ICDD 00-058-0399), respectively.

Table S1. Amount of metal precursors, TOP, and OA used in the synthesis of Pd-Sn nanocatalysts

\begin{tabular}{|c|c|c|c|c|}
\hline Nanocatalyst & $\mathrm{PdBr}_{2}(\mathbf{m g})$ & $\mathbf{S n}(\mathbf{O A c})_{2}(\mathbf{m g})$ & $\left.\mathrm{TOP}_{(\boldsymbol{}} \boldsymbol{L}\right)^{*}$ & $\mathrm{OA}(\boldsymbol{\mu L})^{*}$ \\
\hline $\mathrm{Pd}_{3} \mathrm{Sn}_{2}$ & 27 & 27 & 85 & 15 \\
\hline $\mathrm{Pd}_{2} \mathrm{Sn}$ & 37 & 16 & 90 & 20 \\
\hline $\mathrm{Pd}_{3} \mathrm{Sn}$ & 42 & 9 & 80 & 20 \\
\hline $\mathrm{Pd}_{2} \mathrm{Sn} \mathrm{NCs}$ & 37 & 16 & 90 & 0 \\
\hline $\mathrm{Pd}_{2} \mathrm{Sn} \mathrm{NRs}$ & 37 & 16 & 90 & 10 \\
\hline
\end{tabular}

(*) The overall volume of TOP+OA had to be adjusted in each synthesis in order to obtain monodisperse NPs. 

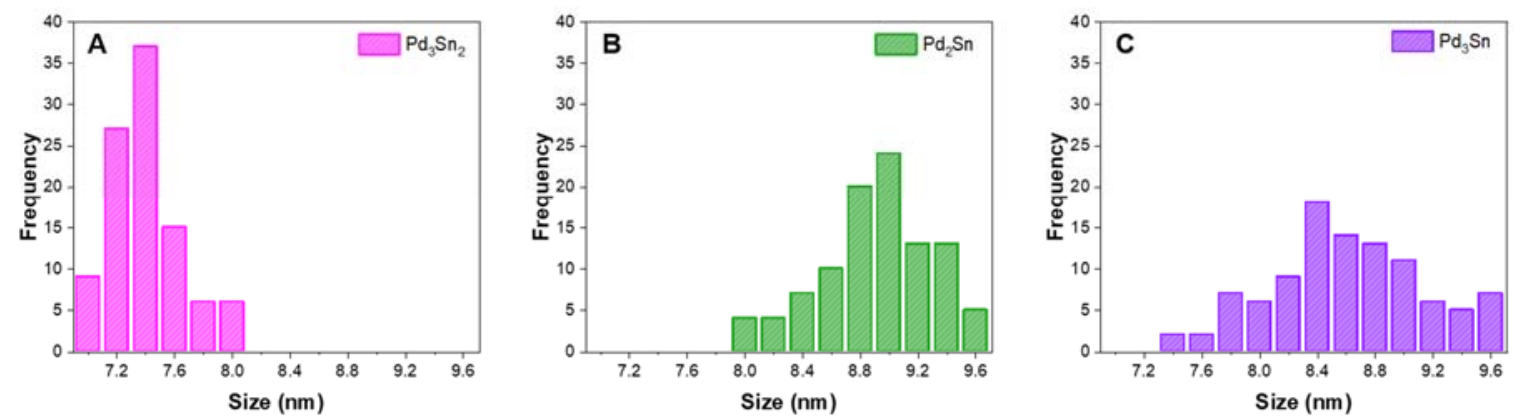

Figure S2. Histograms of size distribution for (A) $\mathrm{Pd}_{3} \mathrm{Sn}_{2}$, (B) $\mathrm{Pd}_{2} \mathrm{Sn}$, and (C) $\mathrm{Pd}_{3} \mathrm{Sn}$.

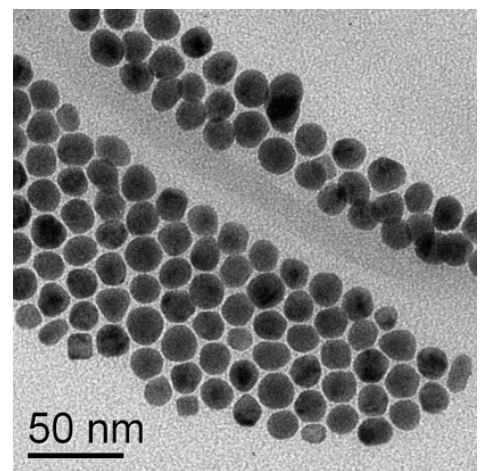

Figure S3. TEM images of $\mathrm{Pd}_{3} \mathrm{Sn}$ when $85 \mu \mathrm{L}$ of TOP and $15 \mu \mathrm{L}$ OA were used.
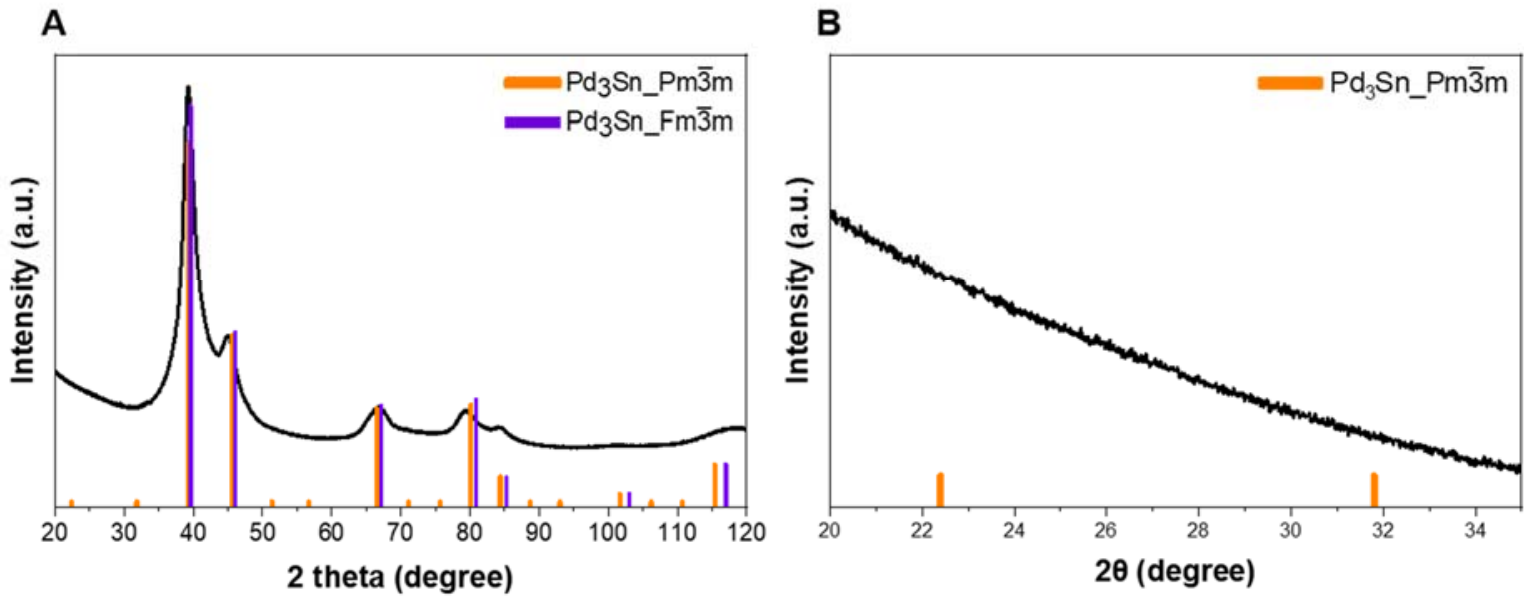

Figure S4. (A) XRD pattern of the synthesized $\mathrm{Pd}_{3} \mathrm{Sn}$ and references for $\mathrm{Pm} \overline{3} \mathrm{~m}$ ICDD: 01-072-2873 and Fm3 3 m - ICDD: 03-066-0022. (B) XRD pattern for $\mathrm{Pd}_{3} S n$ NPs collected by increasing the number of steps as well as the time for each step in the $2 \theta$ range of $20^{\circ}$ to $35^{\circ}$. This experiment was carried out in order to obtain a stronger signal of the superlattice peaks (reducing the background noise and then increasing the resolution of the pattern). However, the superlattice peaks expecting at $22.3^{\circ}$ and $31.8^{\circ}$ do not appear in the pattern. 


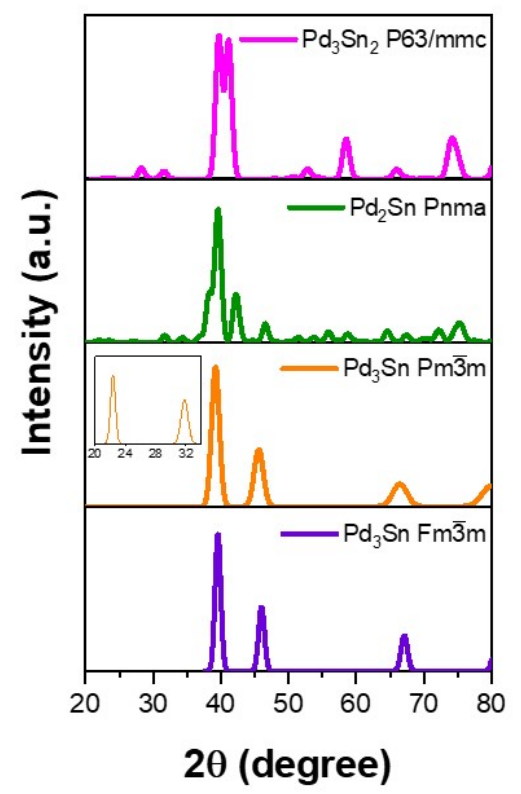

Figure S5. Simulated XRD patterns for all the Pd-Sn NPs.
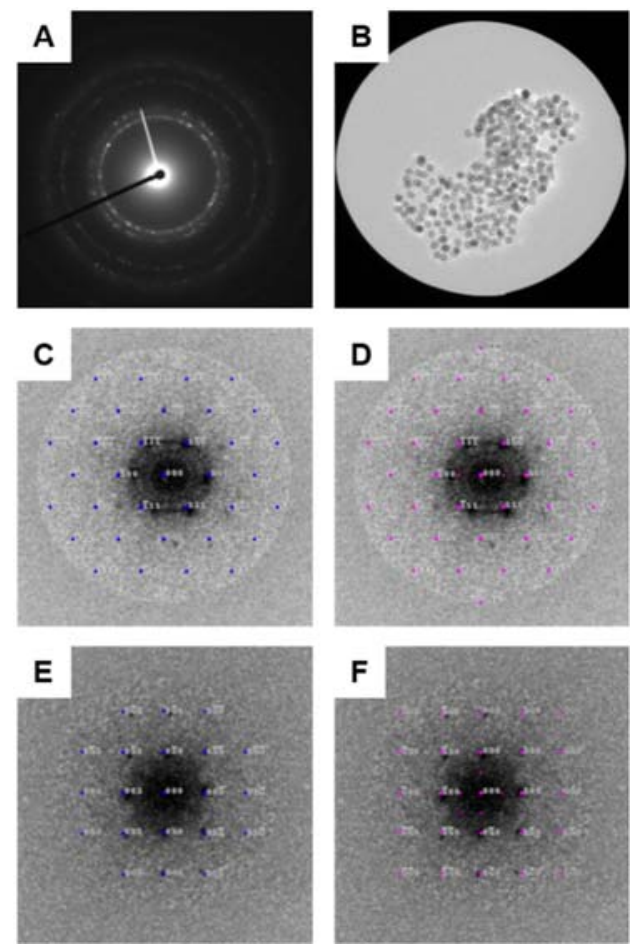

Figure S6. (A) SAED of $\mathrm{Pd}_{3} \mathrm{Sn}$ NPs presented in (B). (C-F) Simulated $\mathrm{Pd}_{3} \mathrm{Sn}$ diffractor patterns for alloy (Fm $\overline{3} \mathrm{~m}$, blue pattern, ICDD: 03-066-0022) and intermetallic (Pm $\overline{3} \mathrm{~m}$, magenta pattern, ICCD: 01-0722873) structures which overlap the corresponding experimental FFT in: (C-D) [0-11] direction and (E-F) [100] direction. 

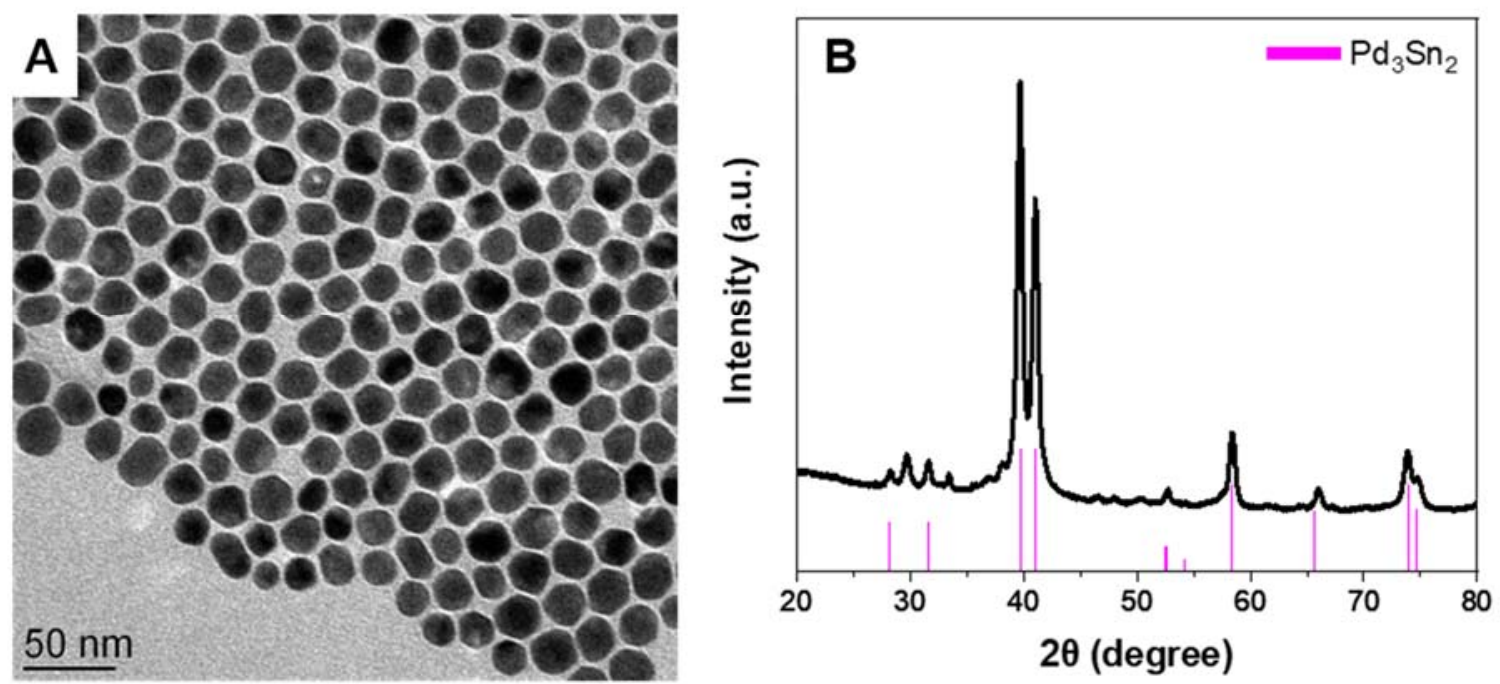

Figure S7. (A) TEM image and (B) XPD pattern of NPs obtained under standard conditions for $\mathrm{Pd}_{3} \mathrm{Sn}_{2}$ except that the temperature of the reaction was $275^{\circ} \mathrm{C}$. Reference for $\mathrm{Pd}_{3} \mathrm{Sn}_{2}$ ICDD: 00-004-0801.
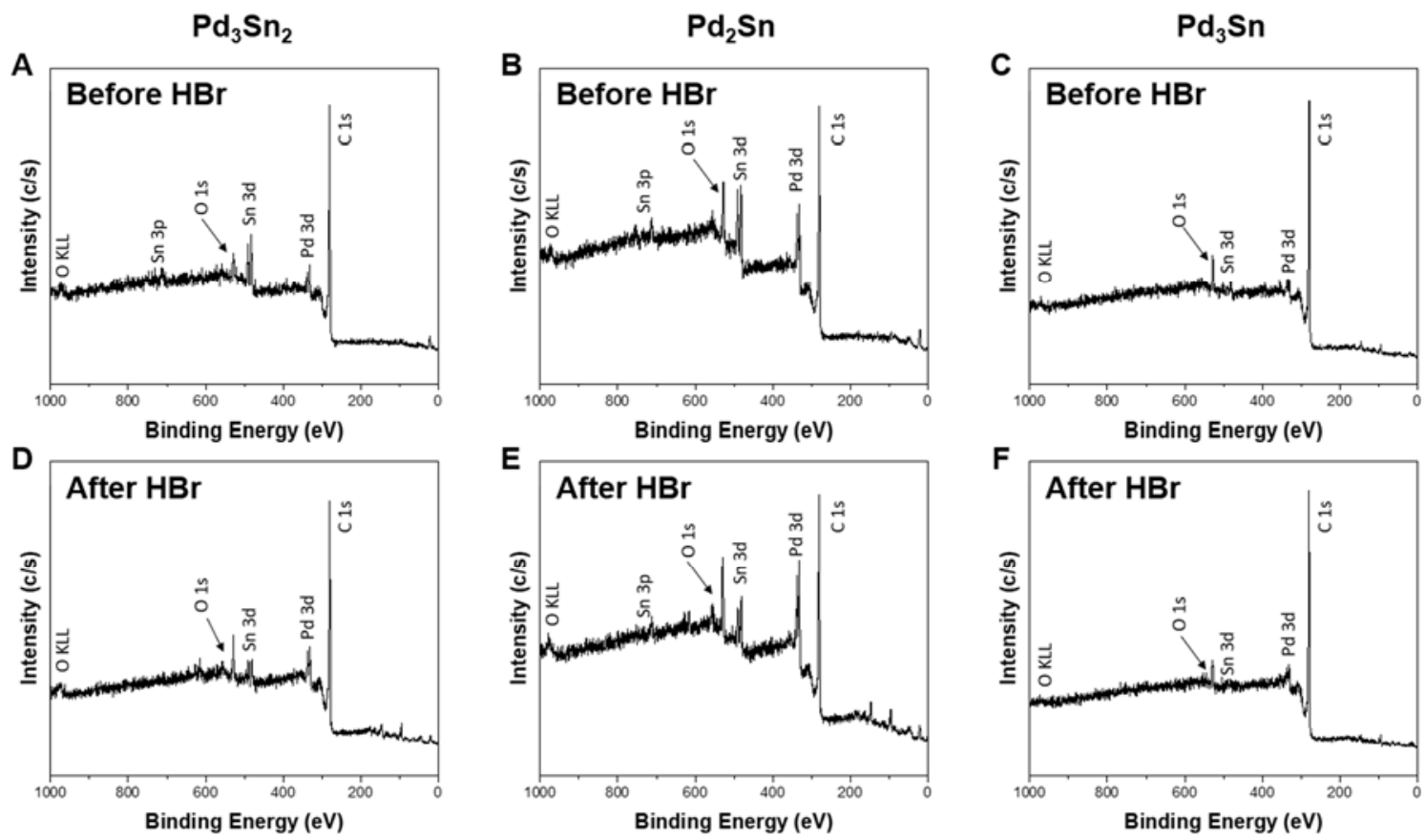

Figure S8. Survey XPS profiles for all Pd-Sn nanocatalyst before (A-C) and after (D-F) of the $\mathrm{Pd}_{3} \mathrm{Sn}_{2}$ (A,D), $\mathrm{Pd}_{2} \mathrm{Sn}(\mathbf{B}, \mathbf{E}), \mathrm{Pd}_{3} \mathrm{Sn}(\mathbf{C}, \mathbf{F})$. 
Table S2. Binding energies of Pd of the three Pd-Sn nanocatalysts

\begin{tabular}{|c|c|c|c|c|}
\hline \multirow{2}{*}{ Sample } & \multicolumn{2}{|c|}{ Initial } & \multicolumn{2}{c|}{$\begin{array}{c}\text { After HBr treatment - } \\
\text { exposed under air for 1 h }\end{array}$} \\
\cline { 2 - 5 } & $\begin{array}{c}3_{\mathrm{d} 5 / 2} \\
(\mathrm{eV})\end{array}$ & $\begin{array}{c}3_{\mathrm{d} 3 / 2} \\
(\mathrm{eV})\end{array}$ & $\begin{array}{c}3_{\mathrm{d} 5 / 2} \\
(\mathrm{eV})\end{array}$ & $\begin{array}{c}3_{\mathrm{d} 3 / 2} \\
(\mathrm{eV})\end{array}$ \\
\hline $\mathbf{P d}_{3} \mathbf{S n}_{2}$ & 336.2 & 341.5 & 336.20 & 341.49 \\
\hline $\mathbf{P d}_{\mathbf{2}} \mathbf{S n}$ & 336.1 & 341.4 & 336.3 & 341.58 \\
\hline $\mathbf{P d}_{3} \mathbf{S n}$ & 336.0 & 341.2 & 335.47 & 340.72 \\
\hline $\mathbf{P d} / \mathbf{C}$ & 335.8 & 341.0 & ----- & ----- \\
\hline
\end{tabular}

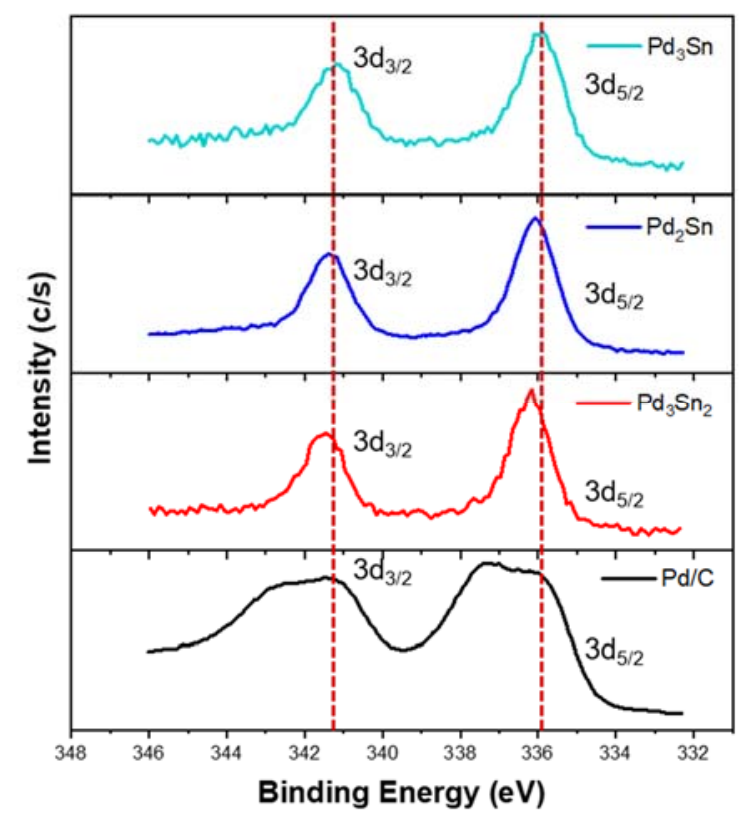

Figure S9. Comparison of the XPS profiles of $\mathrm{Pd} 3 \mathrm{~d}$ for $\mathrm{Pd}_{3} \mathrm{Sn}, \mathrm{Pd}_{2} \mathrm{~S}, \mathrm{Pd}_{3} \mathrm{Sn}_{2}$ and commercial $\mathrm{Pd} / \mathrm{C}$. 

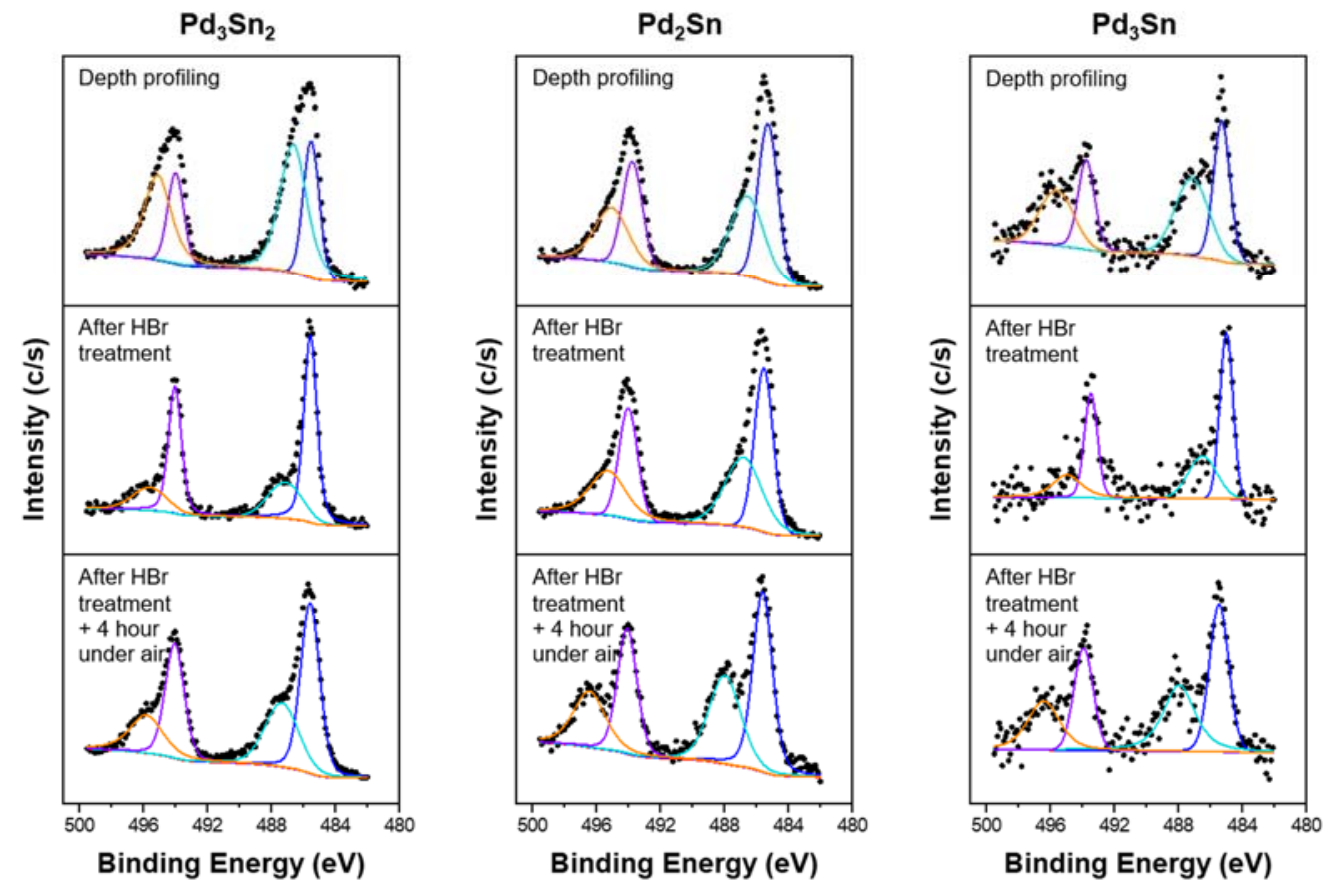

Figure S10. XPS profile for Sn of the Pd-Sn NPs, sputter depth profiling, after treatment with $\mathrm{HBr}$, and after treatment with $\mathrm{HBr}$ and being exposed under air for 4 hours for $\mathrm{Pd}_{3} \mathrm{Sn}_{2}, \mathrm{Pd}_{2} \mathrm{Sn}$ and $\mathrm{Pd}_{3} \mathrm{Sn} \mathrm{NPs}$.
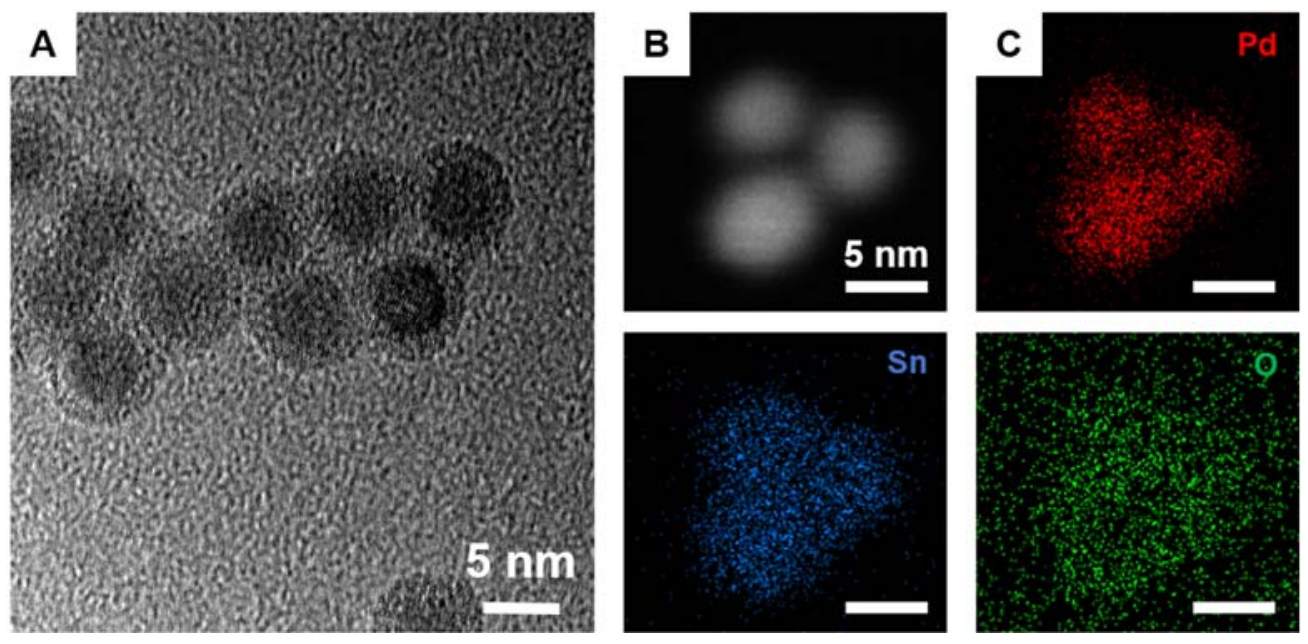

Figure S11. (A) High magnification TEM images (B) STEM and (C) STEM/EDX images for $\mathrm{Pd}_{2} \mathrm{Sn}$. 

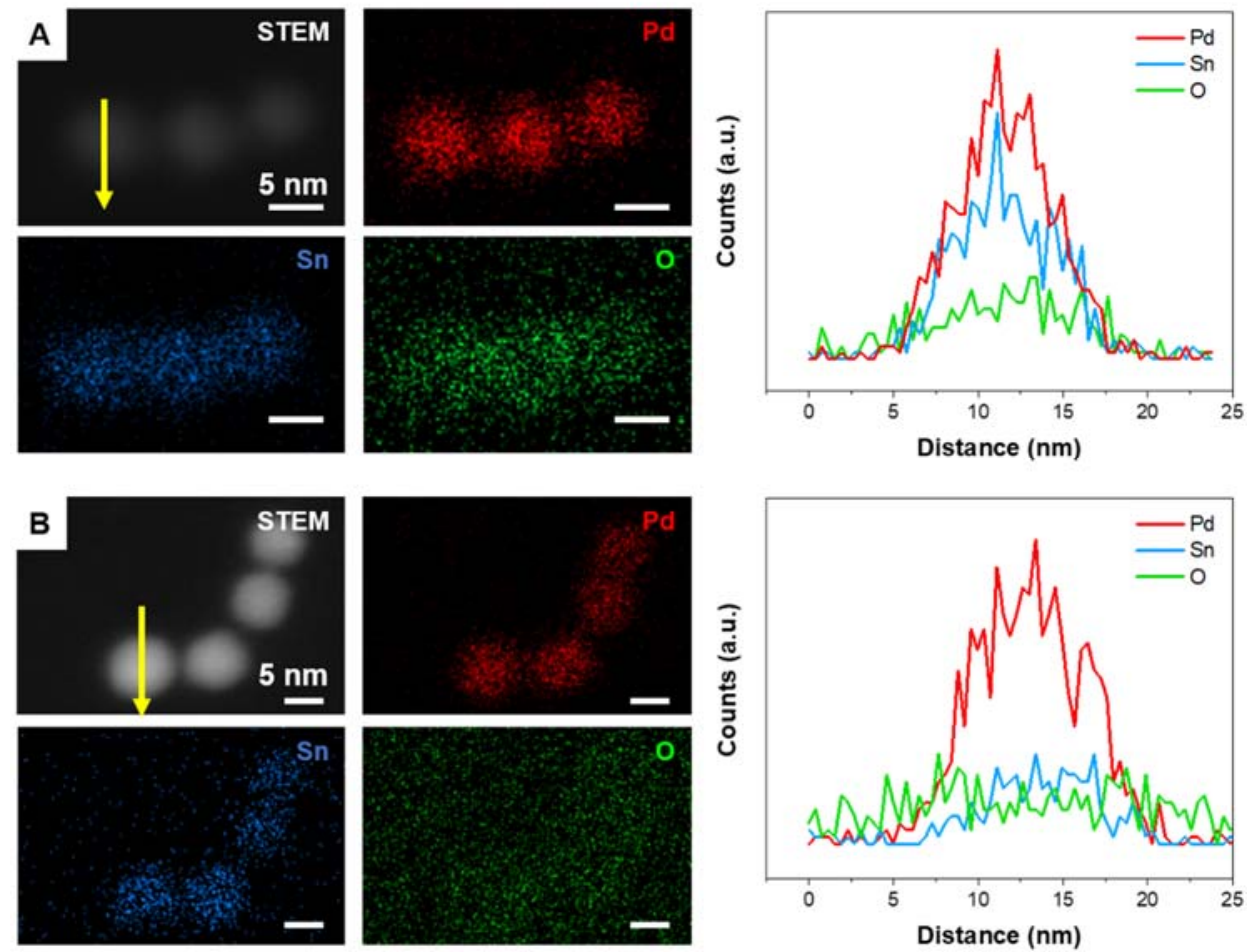

Figure S12. STEM, STEM-EDS, and corresponding line scan for (A) $\mathrm{Pd}_{3} \mathrm{Sn}_{2}$ and (B) $\mathrm{Pd}_{3} \mathrm{Sn}$.
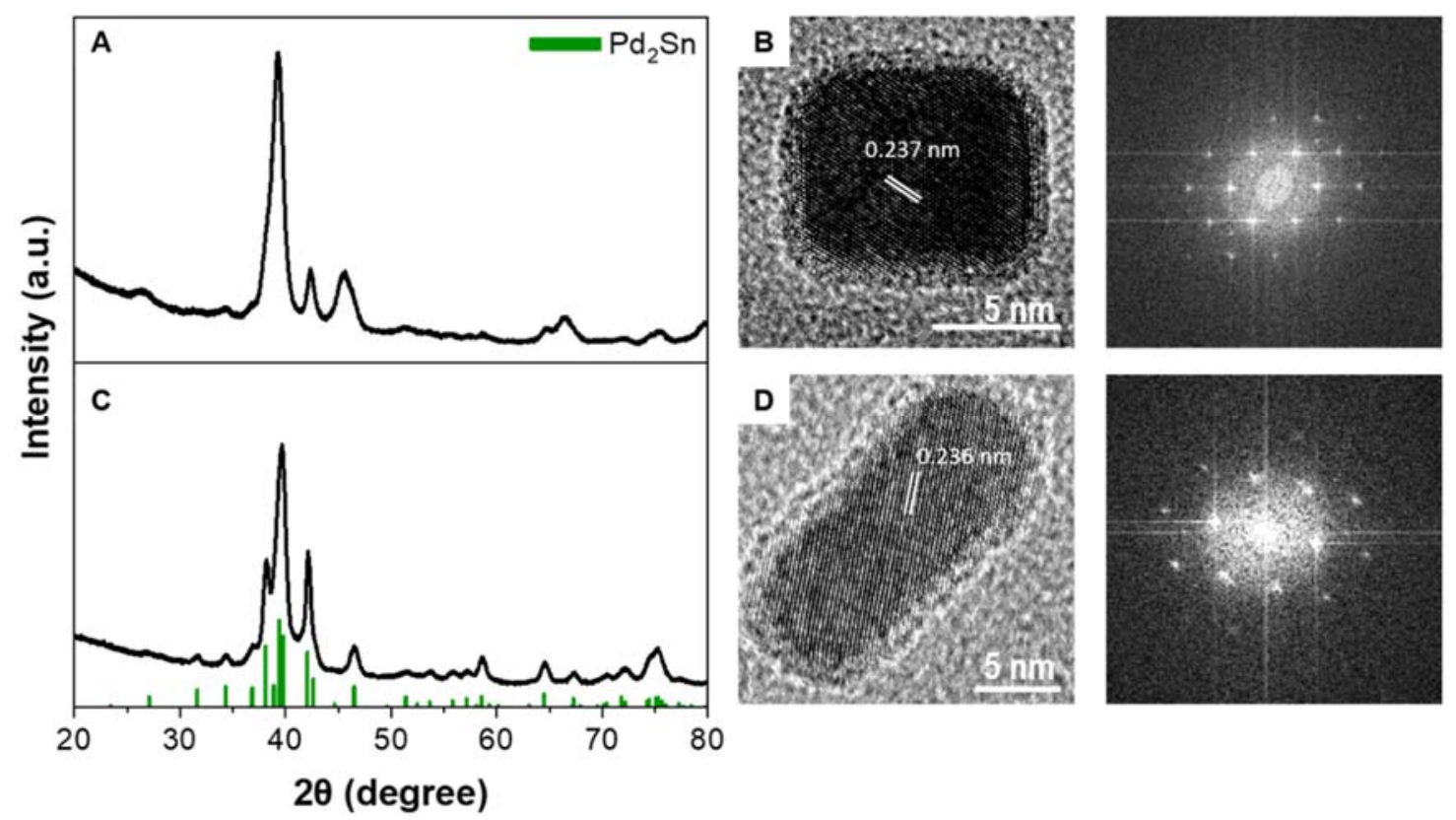

Figure S13. Crystal structure characterization for $\mathrm{Pd}_{2} \mathrm{Sn}$ NPs with shape control. XRD patterns (A,C), HRTEM images and corresponding FFT (B,D) for (A-B) $\mathrm{Pd}_{2} \mathrm{Sn}$ nanorhombohedra and (C-D) $\mathrm{Pd}_{2} \mathrm{Sn}$ nanorods. XRD $\mathrm{Pd}_{2} \mathrm{Sn}$ reference: ICDD 01-076-2812. 

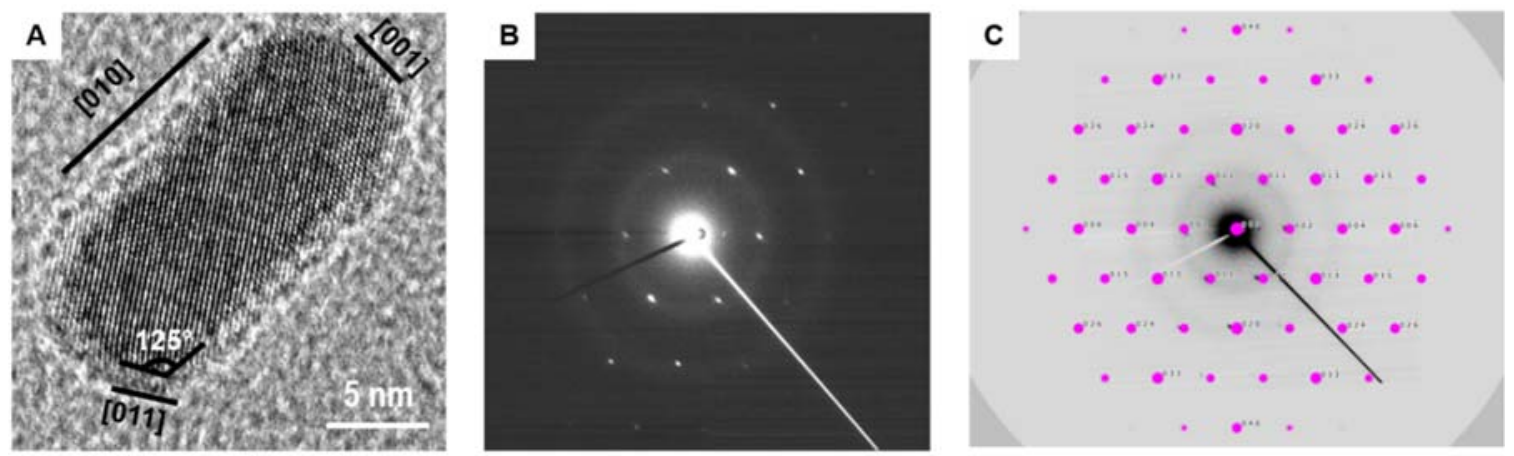

Figure S14. (A) HRTEM of a single $\mathrm{Pd}_{2} \mathrm{Sn}$ nanorod. (B) SAED of (A) and (C) simulated diffraction pattern along the [100] direction which overlaps to the corresponding experimental SAED in (B) showing that particle (A) presents a [010] growth direction. Directions showed in (A) were determined by using the information obtained in $(\mathrm{C})$.

Table S3. Synthetic conditions at which the $\mathrm{Pd}_{2} \mathrm{Sn}$ NPs present in Figure 5 were obtained.

\begin{tabular}{|c|c|c|c|c|c|}
\hline Sample & $\begin{array}{c}\mathbf{P d B r}_{2} \\
(\mathbf{m g})\end{array}$ & $\begin{array}{c}\mathbf{S n}(\mathbf{O A c})_{2} \\
(\mathbf{m g})\end{array}$ & $\begin{array}{c}\text { OLA } \\
(\mathbf{m L})\end{array}$ & $\begin{array}{c}\text { TOP } \\
(\boldsymbol{\mu L})\end{array}$ & $\begin{array}{c}\text { OA } \\
(\boldsymbol{\mu L})\end{array}$ \\
\hline $\mathrm{A}$ & 37 & 16 & 9 & 75 & 25 \\
\hline $\mathrm{B}$ & 37 & 16 & 9 & 80 & 20 \\
\hline $\mathrm{C}$ & 37 & 16 & 9 & 85 & 15 \\
\hline $\mathrm{D}$ & 37 & 16 & 9 & 90 & 10 \\
\hline
\end{tabular}

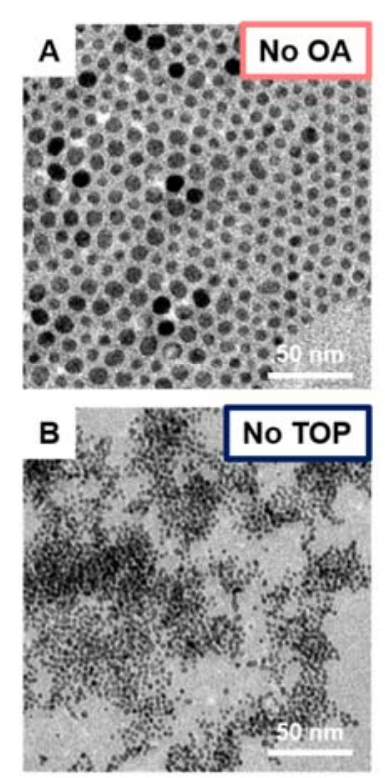

$$
\mathrm{Pd}_{3} \mathrm{Sn}
$$

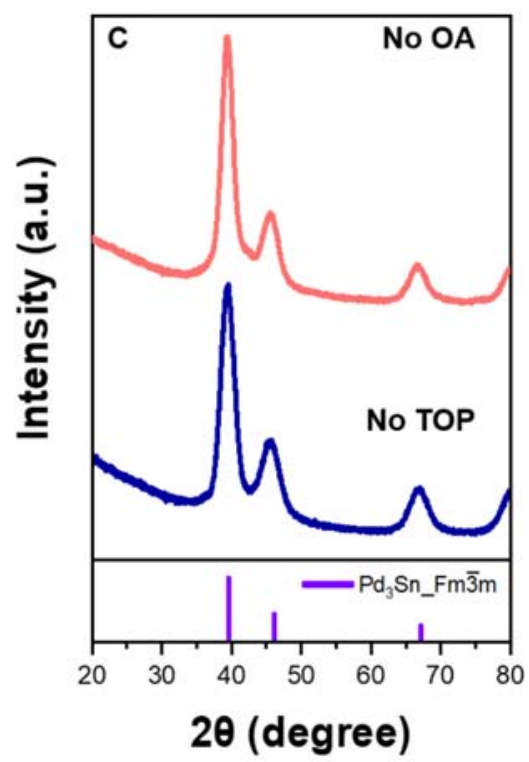

Figure S15. Characterization of NPs obtained from control experiments, where (A-B) are TEM images of NPs when OA and TOP are omitted, respectively. (C) Corresponding XRD diffraction patterns from (AB) and $\mathrm{Pd}_{3} \mathrm{Sn}$ (ICDD: $\mathrm{Fm} \overline{3} \mathrm{~m}$ 03-066-0022) reference. 
$\mathrm{Pd}_{3} \mathrm{Sn}_{2}$
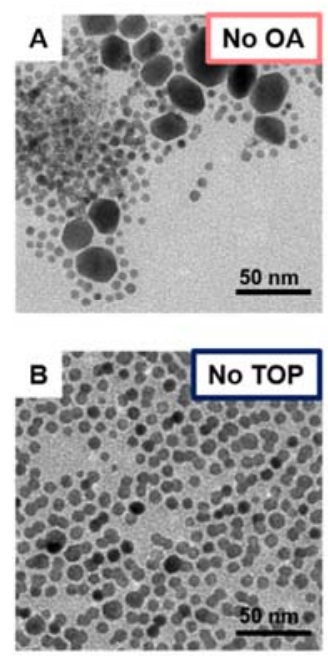

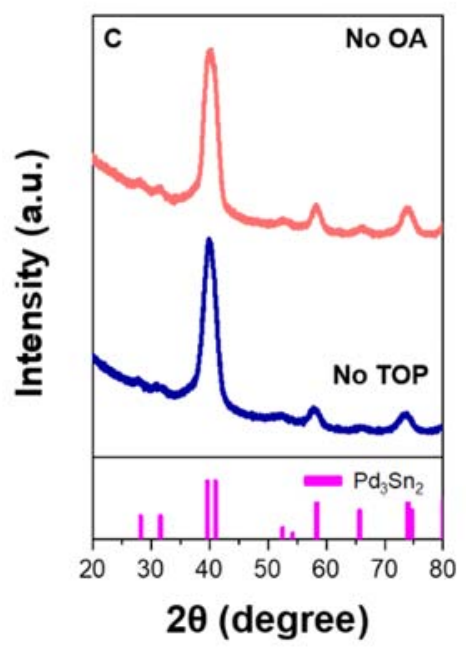

$\mathrm{Pd}_{2} \mathrm{Sn}$

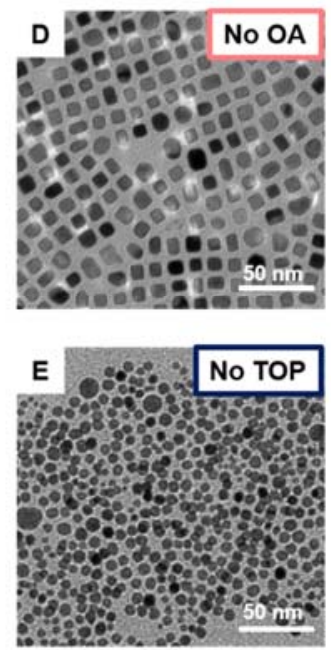

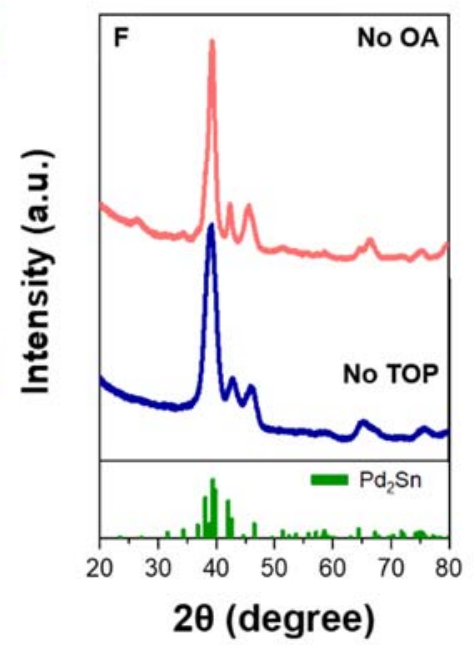

Figure S16. Characterization of NPs obtained from control experiments, where (A-B, D-E) are TEM images of NPs when OA and TOP are omitted, respectively. (C, F). Corresponding XRD diffraction patterns from (A-B, D-E) and $\mathrm{Pd}_{3} \mathrm{Sn}_{2}$ (ICDD 00-004-0801) and $\mathrm{Pd}_{2} \mathrm{Sn}$ (ICDD 01-076-2812) references.

A

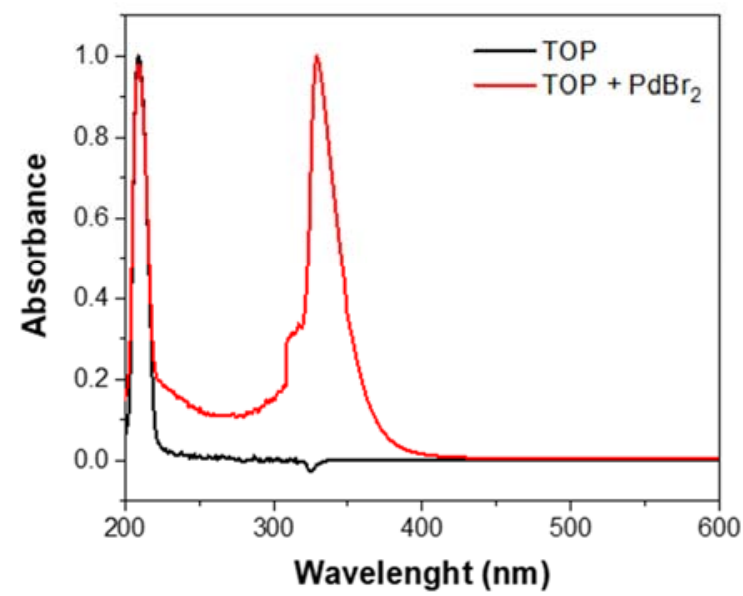

B

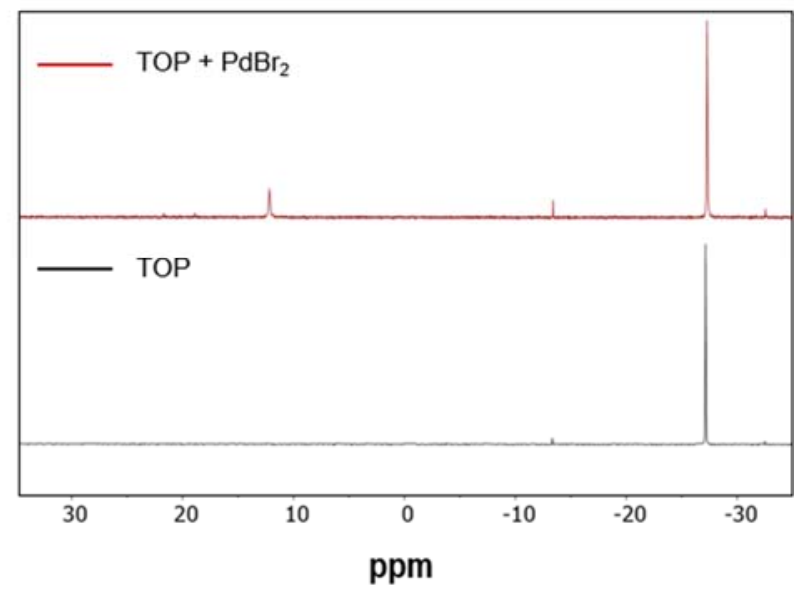

Figure S17. (A) UV- visible spectroscopy and (B) ${ }_{31} \mathrm{P}-\mathrm{NMR}$ in [D8]-acetone of TOP (black, bottom) and $\mathrm{PdBr}_{2}$ mixed with TOP (red, top) 

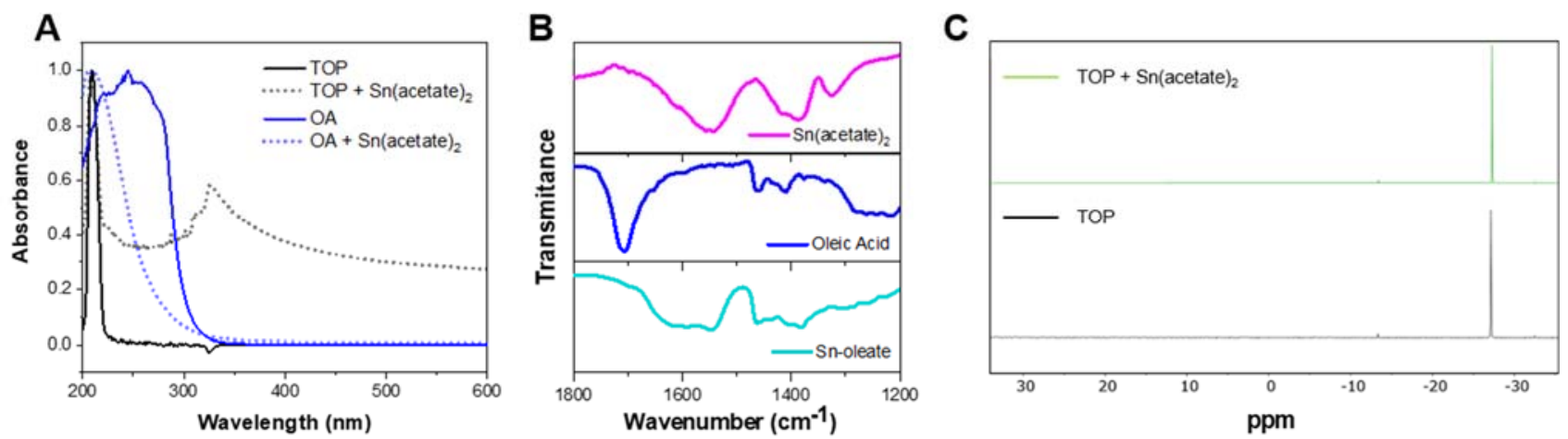

Figure S18. (A) Characterization by UV-visible spectroscopy of TOP, OA, TOP mixed with Sn(acetate)2, and OA mixed with $\mathrm{Sn}(\text { acetate })_{2}$. (B) FTIR Sn (acetate) $)_{2}$, OA, and OA mixed with Sn(acetate) $)_{2}$ (C)

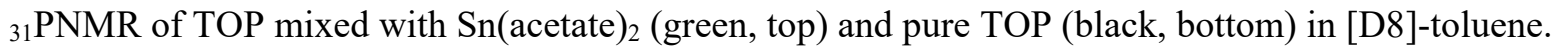
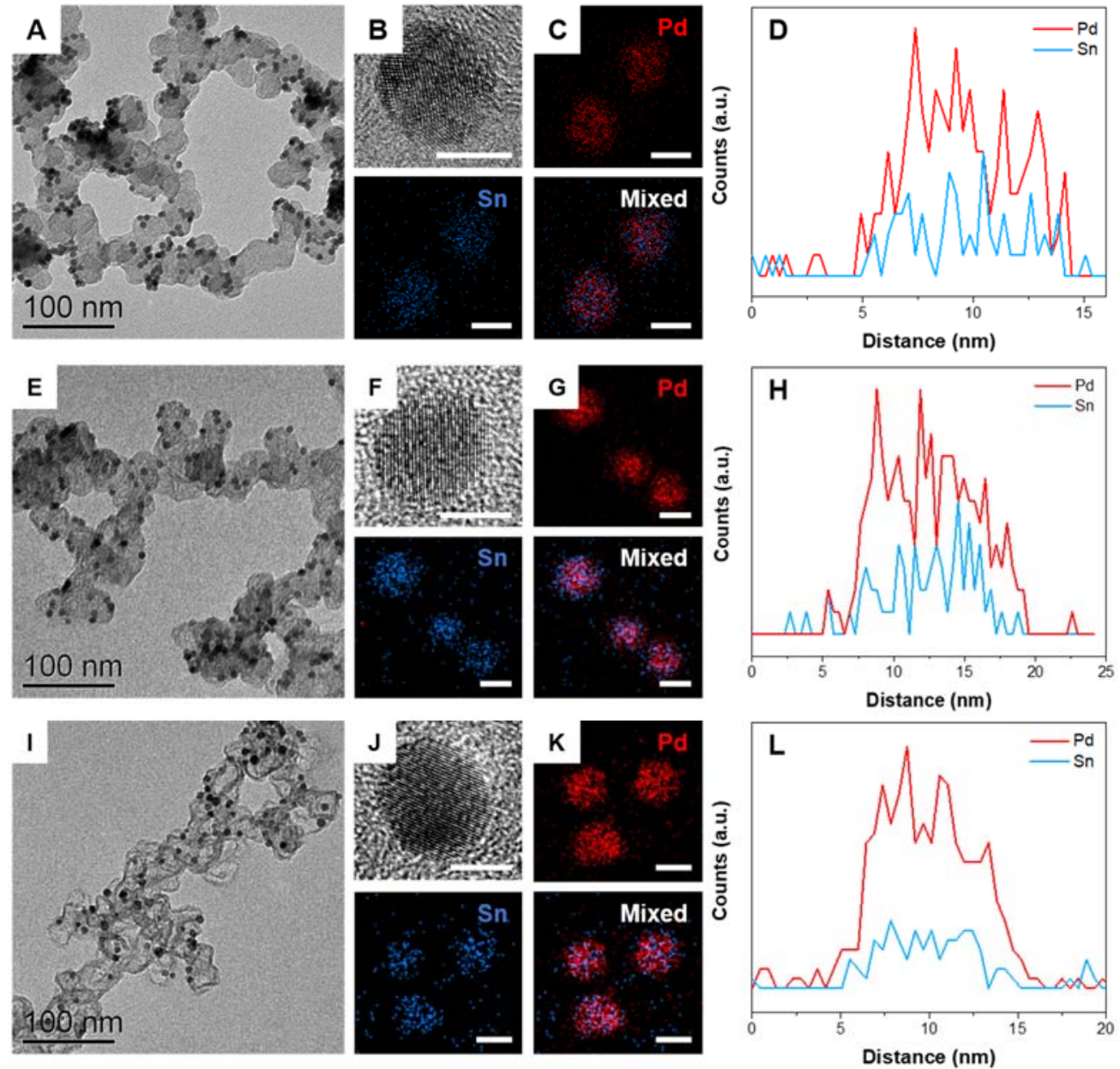

Figure S19. Characterization of the Pd-Sn NPs after treatment with HBr. TEM images of (A) $\mathrm{Pd}_{3} \mathrm{Sn}_{2}$, (E) $\mathrm{Pd}_{2} \mathrm{Sn}$, (I) $\mathrm{Pd}_{3} \mathrm{Sn}$; HRTEM for (B) $\mathrm{Pd}_{3} \mathrm{Sn}_{2}$, (F) $\mathrm{Pd}_{2} \mathrm{Sn}$, (J) $\mathrm{Pd}_{3} \mathrm{Sn}$; STEM/EDX for (C) $\mathrm{Pd}_{3} \mathrm{Sn}_{2},(\mathbf{G}) \mathrm{Pd}_{2} \mathrm{Sn}$, and (K) $\mathrm{Pd}_{3} \mathrm{Sn}$; corresponding line scan for (D) $\mathrm{Pd}_{3} \mathrm{Sn}_{2}$, (H) $\mathrm{Pd}_{2} \mathrm{Sn}$, and (L) $\mathrm{Pd}_{3} \mathrm{Sn}$. Scale bar is $5 \mathrm{~nm}$. 

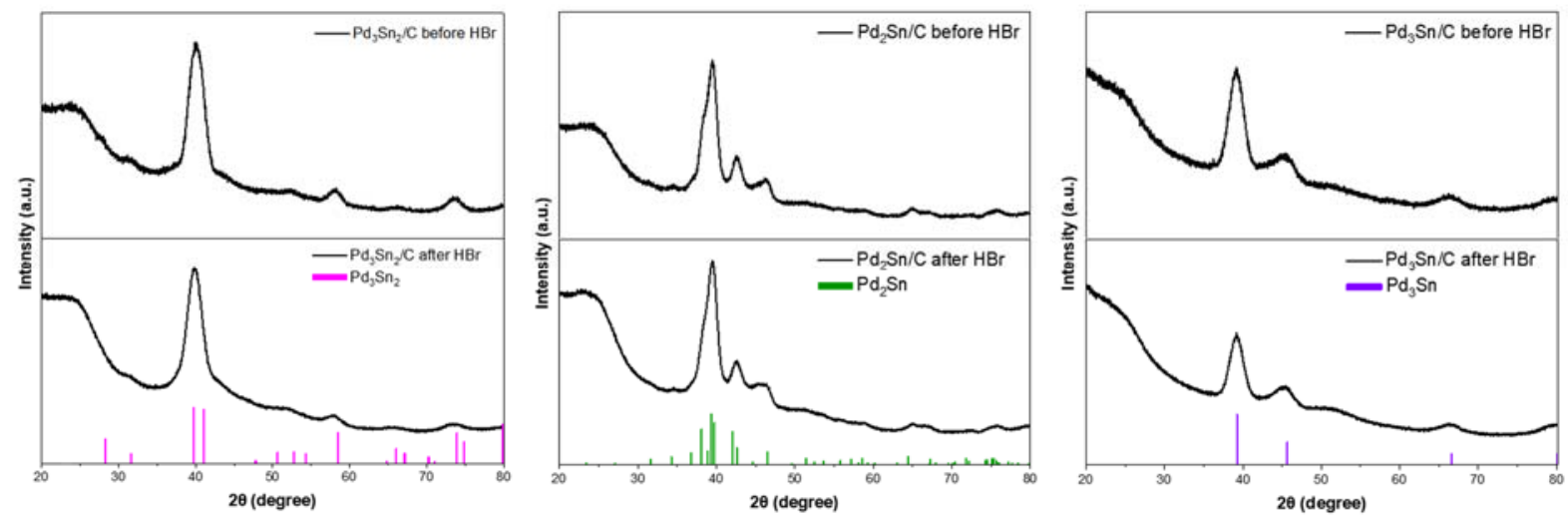

Figure S20. XRD patterns for the Pd-Sn nanocatalysts supported on carbon support before and after treatment with $\mathrm{HBr}$ with their corresponding reference (A) $\mathrm{Pd}_{3} \mathrm{Sn}_{2}$ (ICDD: 00-004-0801); (B) $\mathrm{Pd}_{2} \mathrm{Sn}$ (ICDD: 01-076-2812); (C) $\mathrm{Pd}_{3}$ Sn (ICDD: Fm̄̄m 03-066-0022).
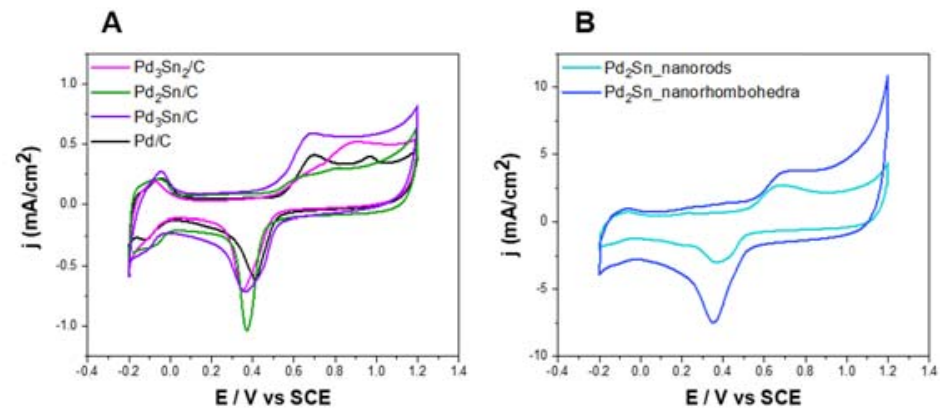

C
\begin{tabular}{|c|c|}
\hline Sample & ECSA $\left(\mathrm{m}^{2} / \mathrm{g}_{\mathrm{Pd}}\right)$ \\
\hline $\mathrm{Pd}_{3} \mathrm{Sn}_{2}$ & 13.0 \\
\hline $\mathrm{Pd}_{2} \mathrm{Sn}$ & 5.3 \\
\hline $\mathrm{Pd}_{3} \mathrm{Sn}$ & 7.6 \\
\hline $\mathrm{Pd}_{2} \mathrm{Sn}$ nanorhombohedra & 0.3 \\
\hline $\mathrm{Pd}_{2} \mathrm{Sn}$ nanorods & 0.8 \\
\hline $\mathrm{Pd}$ & 36.3 \\
\hline
\end{tabular}

Figure S21. Cyclic voltammograms collected in Ar-purged $0.1 \mathrm{M} \mathrm{H}_{2} \mathrm{SO}_{4}$ for (A) $\mathrm{Pd}_{3} \mathrm{Sn}_{2} / \mathrm{C}, \mathrm{Pd}_{2} \mathrm{Sn} / \mathrm{C}$, $\mathrm{Pd}_{3} \mathrm{Sn} / \mathrm{C}, \mathrm{Pd} / \mathrm{C}$ and (B) $\mathrm{Pd}_{2} \mathrm{Sn} / \mathrm{C}$ nnanorhombohedra and $\mathrm{Pd}_{2} \mathrm{Sn} / \mathrm{C}$ _nanorods; (C) calculated electrochemically active surface area (ECSA). 

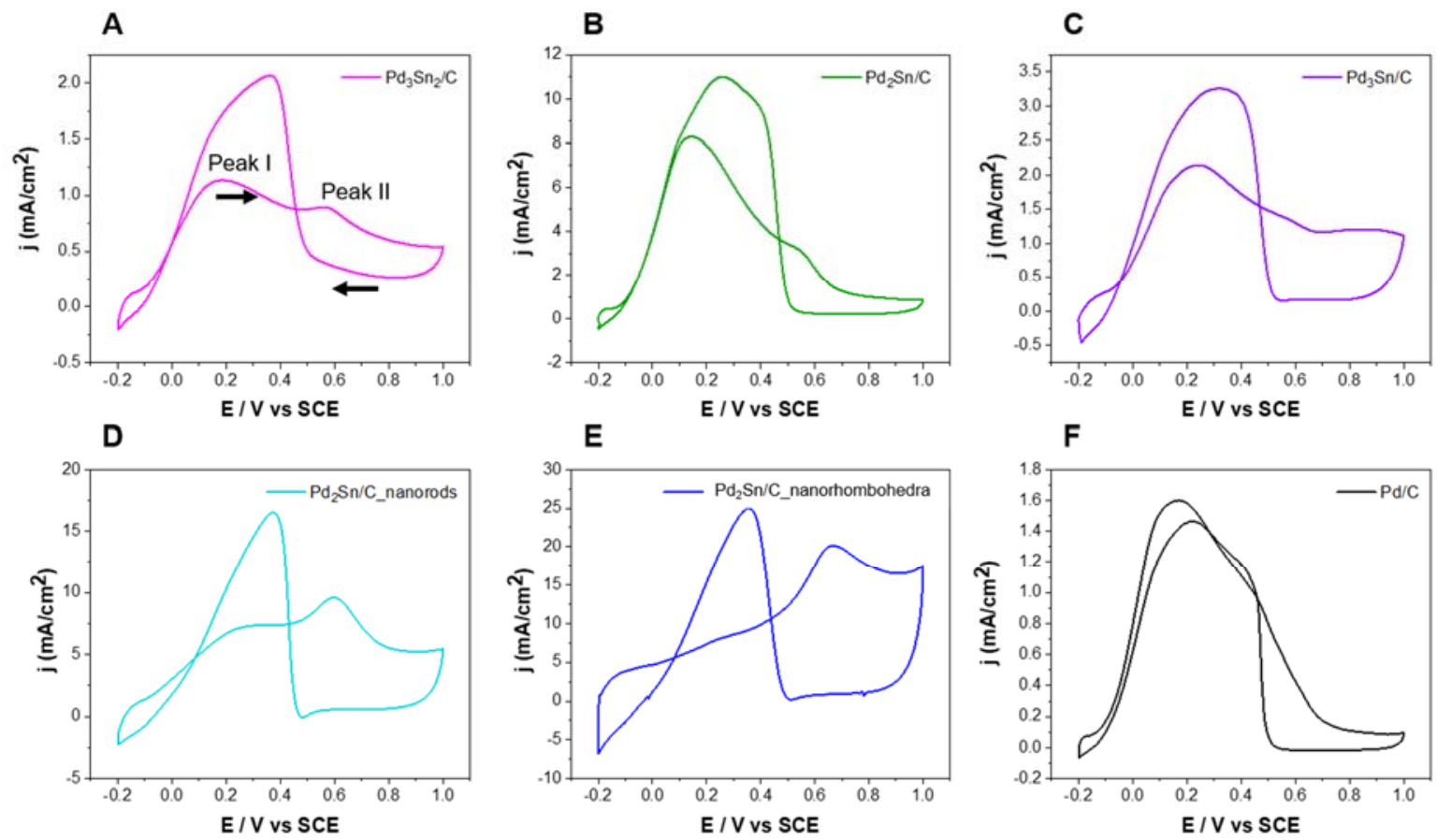

Figure S22. FAEO profiles collected in Ar-purged $0.5 \mathrm{M} \mathrm{HCOOH}$ and $0.5 \mathrm{M} \mathrm{H}_{2} \mathrm{SO}_{4}$ at $50 \mathrm{mV} / \mathrm{s}$ for (A) $\mathrm{Pd}_{3} \mathrm{Sn}_{2} / \mathrm{C} \_\mathrm{NCs}$, (B) $\mathrm{Pd}_{2} \mathrm{Sn} / \mathrm{C} \_\mathrm{NRs}$, (C) $\mathrm{Pd}_{3} \mathrm{Sn} / \mathrm{C}$, (D) $\mathrm{Pd}_{2} \mathrm{Sn} / \mathrm{C}$, nanorods (E) $\mathrm{Pd}_{3} \mathrm{Sn} / \mathrm{C}$ nanorhombohedra, and (F) $\mathrm{Pd} / \mathrm{C}$.
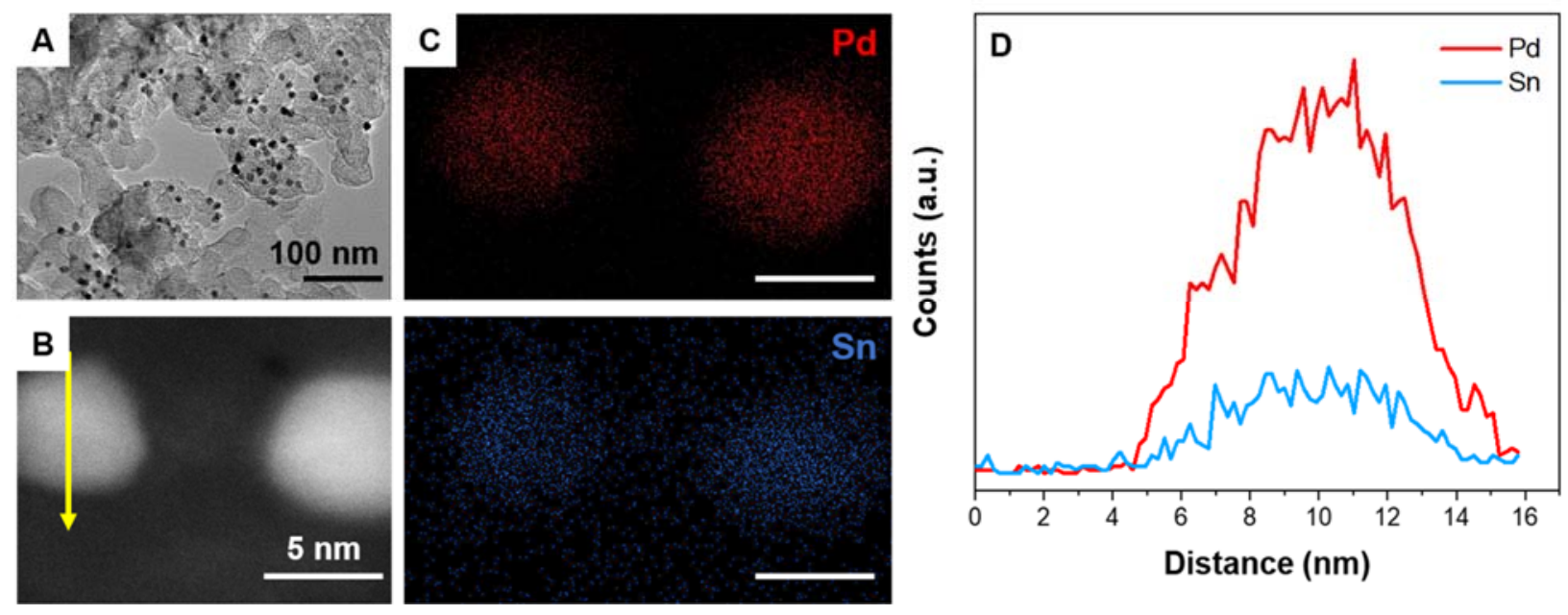

Figure S23. (A) TEM, (B) STEM, (C) STEM/EDX, images and (D) corresponding line scan of $\mathrm{Pd}_{3} \mathrm{Sn}$ NPs collected after electrooxidation of formic acid. 